\title{
PURIFICAÇÃO DE BIODIESEL POR SORÇÃO EM CINZA DE CASCA DE ARROZ E CINZA DO BAGAÇO DA CANA-DE- AÇÚCAR
}

\author{
D. C. F. $\operatorname{ROSA}^{1}$, J. O. WOLFGRAMM ${ }^{1}$, A. E. $\operatorname{COSTA}^{1}$ e J. K. ANDREAZZA ${ }^{1}$ \\ ${ }^{1}$ Centro Universitário Tupy - UNISOCIESC, Departamento de Engenharia Química \\ E-mail para contato: adriana.costa@ sociesc.org.br
}

\begin{abstract}
RESUMO - O biodiesel é um biocombustível usualmente produzido pela reação de transesterificação. Após a sua obtenção, é necessário realizar um processo de purificação para remover traços de glicerol livre (GL), dentre outros contaminantes. Nesse trabalho, avaliou-se a remoção de GL do biodiesel por sorção em três diferentes materiais, sendo eles um comercial - o Magnesol ${ }^{\circledR}-\mathrm{e}$ dois alternativos - cinza de casca de arroz (CCA) e cinza do bagaço da cana-deaçúcar (CBC), para fins de comparação. O biodiesel foi produzido por transesterificação, a partir de óleo residual de fritura e etanol, usando catálise mista. Para avaliar a purificação, foram realizados experimentos de sorção de GL em batelada e, com o auxílio de modelos empíricos, avaliou-se o comportamento dos dados cinéticos. Os três materiais avaliados foram eficientes em remover GL do biodiesel, sendo que o Magnesol ${ }^{\circledR}$ atingiu a especificação da ANP $(0,02 \%$ de GL em massa) em 30 minutos de sorção, seguido pela CCA e pela CBC, que atingiram a especificação em cerca de 60 e 120 minutos de sorção, respectivamente.
\end{abstract}

\section{INTRODUÇÃO}

A preocupação com a emissão de gases poluentes oriundos da queima em motores movidos a combustível derivado de petróleo, bem como o aumento do consumo, trouxe a necessidade do desenvolvimento de combustíveis a partir de fontes renováveis, os quais são denominados biocombustíveis. Dentre estes, biodiesel ganha destaque como possível sucessor do óleo diesel, devido principalmente à semelhança de propriedades físicas e químicas, visto que não são necessárias alterações nos motores de ciclo diesel quando o biodiesel é usado em misturas com o diesel até a proporção de $20 \%$ em volume. Quimicamente, o biodiesel é um combustível composto por ésteres monoalquilícos de ácidos graxos de cadeia longa, derivados de óleos vegetais ou gorduras animais, obtido geralmente por reação de transesterificação, onde ocorre a formação do éster monoalquilíco (biodiesel) e glicerol (COSTA NETO et al., 2000; DE PAULA et al., 2011; OM TAPANE et al., 2013).

O óleo residual de processamentos domésticos, comerciais e industriais foi uma das primeiras fontes alternativas de matérias-primas apontadas para a produção de biodiesel, pois esse material não apenas deixará de ser rejeitado de modo inadequado como também será reutilizado no processo de transesterificação (SILVA e FREITAS, 2008; OM TAPANES et 
al., 2013), além do seu baixo custo e disponibilidade, visto que a produção de biodiesel a partir de óleos virgens de alta qualidade torna seu preço inviável frente ao diesel de petróleo (GUI, LEE e BHATIA, 2008). Quanto ao álcool utilizado no processo, apesar do metanol ser largamente empregado nas indústrias, a substituição do metanol pelo etanol no processo também traz benefícios, visto que o etanol brasileiro é de procedência renovável, possibilitando a obtenção de um biodiesel verdadeiramente renovável, apresentando menor toxicidade (DE PAULA et al., 2011). Independentemente do modo de produção do biodiesel, é necessário um método eficaz de purificação final para este atenda às especificações regulamentadas pela Agência Nacional do Petróleo, Gás Natural e Biocombustíveis (ANP, 2012).

O método mais utilizado nas indústrias para a purificação final do biodiesel é a lavagem aquosa. Porém, essa possui desvantagens como a abundante utilização de água no processo e a geração significativa de efluentes, aumentando o custo e o tempo de processo. Há, portanto, necessidade de viabilizar um processo de purificação do biodiesel que evite tais problemas (DE PAULA et al., 2011).

Outro método que possibilita a remoção de impurezas do biodiesel com o intuito de reduzir a geração significativa de efluentes, é a sorção (lavagem a seco), que consiste basicamente em explorar as características que alguns sólidos (adsorventes) têm de reter em sua superfície as impurezas que devem ser removidas, atraindo-as quimicamente ou fisicamente (ATKINS, 2002; ROYER, 2008). Atualmente, existem adsorventes comercializados especificamente para a purificação do biodiesel, como o Magnesol ${ }^{\circledR}$ e a resina Purolite ${ }^{\circledR}$ PD206, entre outros (DE PAULA et al., 2011). Porém, estudos que avaliem adsorventes alternativos na purificação do biodiesel produzido com etanol são escassos.

Desse modo, nesse estudo avaliou-se a remoção de traços de glicerol livre (GL) do biodiesel usando dois materiais alternativos, cinza de cascas de arroz (CCA) e cinza do bagaço de cana (CBC). Também foi selecionado um adsorvente comercializado especificamente para esse fim, o Magnesol ${ }^{\circledR}$, de modo a comparar a eficiência dos materiais alternativos.

\section{MATERIAIS E MÉTODOS}

\subsection{Biodiesel Etílico}

O biodiesel usado nos ensaios de purificação foi produzido através de reação de transesterificação, com álcool etílico e óleo residual de frituras (relação molar de álcool:óleo 6:1) e catálise mista homogênea.

Anteriormente a cada reação preparou-se o alcóxido, com hidróxido de sódio $(\mathrm{NaOH})$ e álcool etílico, em agitação a temperatura ambiente por 2 horas, deixando em repouso por 24 horas. $\mathrm{O}$ óleo de cocção passou por um pré-tratamento com filtração a vácuo para retirada de material particulado, passando por secagem com sulfato de magnésio para remoção do excesso de umidade, e novamente filtrado a fim de remover o sulfato. Após a filtração adicionou-se ácido oxálico ao óleo filtrado sob agitação mecânica, à temperatura de $70^{\circ} \mathrm{C}$. Em seguida, adicionou-se o alcóxido (pré-aquecido a $50^{\circ} \mathrm{C}$ ) e deixou-se a reação de 
transesterificação ocorrer por 2 horas. Após a reação, as fases de álcool não reagido, biodiesel e glicerina foram separadas em um funil de decantação por 24 horas. Após esse período, retirou-se a glicerina do funil. Em seguida o álcool não reagido foi separado do biodiesel por evaporação a vácuo, em um rota-evaporador. Na Tabela 1, estão apresentadas as propriedades iniciais do biodiesel.

Tabela 1 - Propriedades iniciais do biodiesel etílico produzido.

\begin{tabular}{|c|c|}
\hline $\begin{array}{c}\text { Densidade }-\rho \\
(\mathrm{g} / \mathrm{mL})\end{array}$ & $\begin{array}{c}\text { Glicerina livre }- \\
\text { GL }(\% \text { massa })\end{array}$ \\
\hline 0,877 & 0,251 \\
\hline
\end{tabular}

\subsection{Adsorventes}

Foram selecionados dois materiais alternativos com propriedades adsortivas para a remoção de traços de glicerol livre (GL) do biodiesel: a cinza da casca do arroz e a cinza do bagaço da cana-de-açúcar. Como padrão para comparação de eficiências foi utilizado o adsorvente comercial Magnesol ${ }^{\circledR}$.

Cinza da casca do arroz (CCA): As amostras de cinzas das cascas do arroz foram fornecidas pela Urbano Agroindustrial LTDA para os testes de sorção, o valor é R $\$ 2,00$ uma embalagem com aproximadamente onze quilos.

Cinza do bagaço da cana-de-açúcar (CBC): O bagaço da cana de açúcar foi calcinado em mufla com temperatura pré-determinada de $700^{\circ} \mathrm{C}$ por aproximadamente 3 horas. $\mathrm{O}$ material foi triturado para a diminuição da área superficial e em seguida passou por peneiramento para a seleção das partículas, sendo armazenado em dessecador até a utilização para os ensaios de sorção.

Magnesol $^{\circledR}:$ As amostras foram fornecidas pela empresa Braschemical, o custo do material é de US\$7,90/ kg, sendo vendido com embalagem mínima de 22,68 kg.

\subsection{Cinética de Sorção}

Ensaios cinéticos: Os experimentos foram realizados em batelada a temperatura ambiente, em duplicata. Primeiramente, adicionou-se 4,5 g de adsorvente a $250 \mathrm{~mL}$ de biodiesel, com agitação magnética. Em seguida, foram retiradas alíquotas de 2,5ml em tempos pré-estabelecidos de 5, 15, 30, 60, 90, 120 e 180 minutos. As amostras foram submetidas a centrifugação por 20 minutos. Os teores de GL foram determinados por cromatografia gasosa, conforme a norma EN 14105. Realizou-se o levantamento da curva da cinética de sorção de glicerol livre para os três adsorventes (CCA, CBC e Magnesol).

Modelos cinéticos: Foram testados três modelos empíricos para avaliar o comportamento das cinéticas de sorção: modelo de pseudo-primeira ordem, pseudo-segunda ordem e difusão intraparticular. 
O modelo de pseudo-primeira equivale à equação de Lagergren, cuja forma linearizada é apresentada na Equação 1. Se os dados experimentais forem bem representados por esse modelo, a plotagem de $\log \left(\mathrm{q}_{\mathrm{e}}-\mathrm{q}_{\mathrm{t}}\right)$ versus $\mathrm{t}$ apresentará comportamento linear.

$$
\log \left(q_{e}-q_{t}\right)=\log \left(q_{e}\right)-\frac{k_{1}}{2,303} t
$$

O modelo de pseudo-segunda ordem linearizado é apresentado na Equação 2. Caso este modelo represente bem os dados experimentais, a plotagem de $t / q_{t}$ versus $t$ deve resultar em comportamento linear.

$$
\frac{t}{q_{t}}=\frac{1}{k_{2} q_{e}^{2}}+\frac{1}{q_{e}} t
$$

O modelo de difusão intraparticular é apresentado na Equação 3. Tal como para os modelos anteriores, caso este modelo represente bem os dados experimentais, um gráfico de $t^{1 / 2}$ versus $q_{t}$ deve apresentar comportamento linear.

$$
q_{t}=k_{i} t^{1 / 2}+C
$$

\section{RESULTADOS E DISCUSSÕES}

Na Figura 1 são apresentados os dados experimentais de sorção de traços de glicerol livre (GL) presente no biodiesel sobre cinza de casca de arroz (CCA), cinza do bagaço de cana-de-açúcar (CBC) e Magnesol ${ }^{\circledR}$.

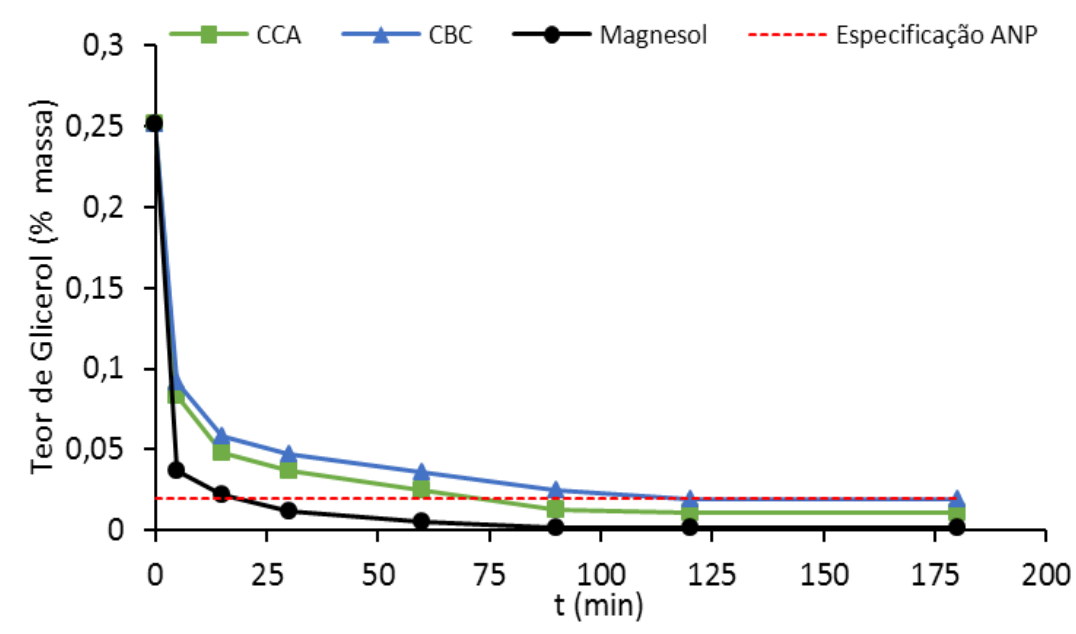

Figura 1 - Dados experimentais de sorção de GL presente no biodiesel sobre CCA, CBC e Magnesol ${ }^{\circledR}$.

Na Figura 1 é possível observar que a sorção foi mais rápida para o Magnesol $^{\circledR}$, atingindo o equílibrio em cerca de 60 minutos e atendendo à especificações da ANP para GL (0,02\% em massa) em cerca de 30 minutos. Os desempenhos dos materiais alternativos foram próximos ao do Magnesol ${ }^{\circledR}$, embora levemente inferiores: os equilíbrios de sorção da CCA e 
da CBC foram atingidos em cerca de 90 e 120 minutos, respectivamente. A especifição da ANP foi atendida em cerca de 60 e 90 minutos, respectivamente.

Na Figura 2 os dados de sorção foram plotados de acordo com o modelo de pseudoprimeira ordem linearizado (Equação 1). Observa-se que este modelo não representou bem os dados experimentais.

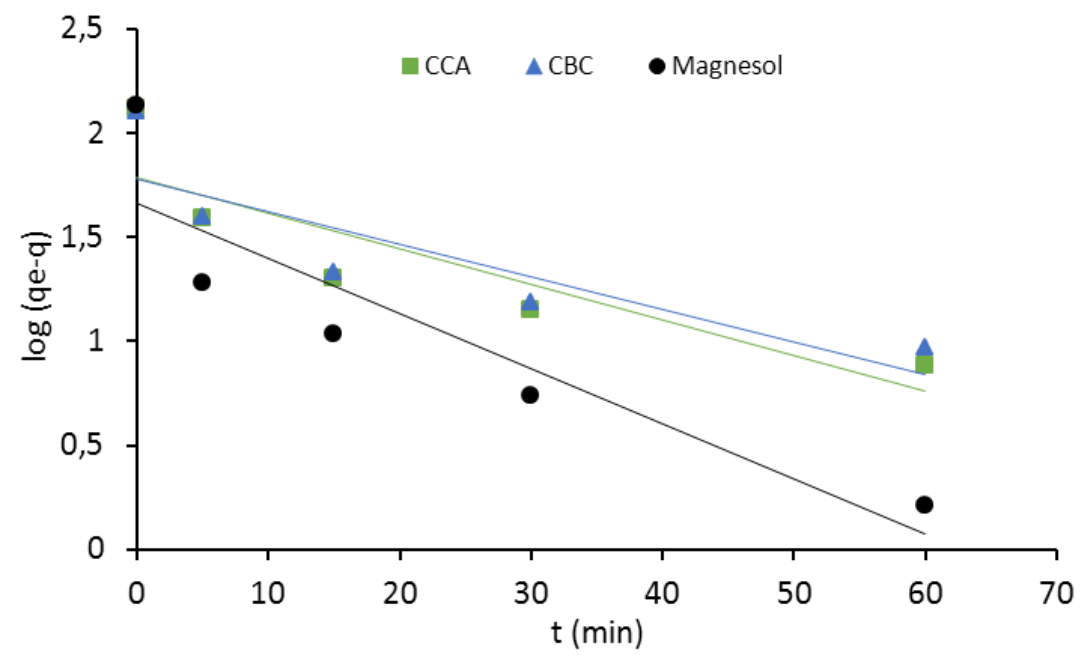

Figura 2 - Ajustes com o modelo cinético de pseudo-primeira ordem.

Na Tabela 2 são apresentados os coeficientes de regressão para os três materiais testados, confirmando esse fato.

Tabela 2 - Coeficientes de regressão linear para o modelo de pseudo-primeira ordem.

\begin{tabular}{|l|c|c|c|}
\hline Adsorvente & Magnesol $^{\circledR}$ & CBC & CCA \\
\hline Coef. de Regressão $\left(\mathrm{R}^{2}\right)$ & 0,8157 & 0,7618 & 0,7739 \\
\hline
\end{tabular}

Na Figura 3 os dados de sorção foram plotados de acordo com o modelo de pseudosegunda ordem linearizado (Equação 2). É possível observar que o modelo representou satisfatoriamente os resultados experimentais, para os três materiais avaliados. 


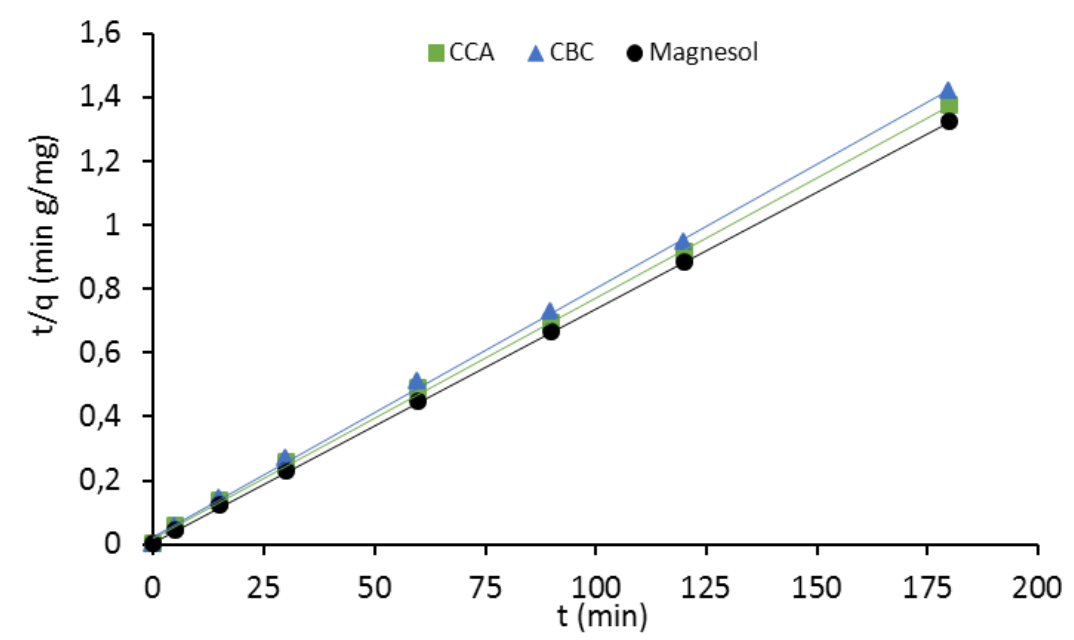

Figura 3 - Ajustes com o modelo cinético de pseudo-segunda ordem.

$\mathrm{Na}$ Tabela 3 são apresentadas as capacidades adsortivas experimentais ( $\mathrm{q}_{\mathrm{e}}$ exp.) e os parâmetros do ajuste pelo modelo de pseudo-segunda ordem (capacidade adsortiva calculada - $\mathrm{q}_{\mathrm{e}}$ calc.; constante de velocidade do modelo de pseudo-segunda ordem $-\mathrm{K}_{2}$ e coeficiente de regressão $-\mathrm{R}^{2}$ ).

Tabela 3 - Coeficientes de cinética do modelo de pseudo-segunda ordem.

\begin{tabular}{|l|c|c|c|c|}
\hline Adsorventes & $\mathrm{q}_{\mathrm{e}}$ exp. $(\mathrm{mg} / \mathrm{g})$ & $\mathrm{q}_{\mathrm{e}}$ calc. $(\mathrm{mg} / \mathrm{g})$ & $\mathrm{k}_{2}$ (g/mg.min) & $\mathrm{R}^{2}$ \\
\hline Magnesol $^{\circledR}$ & 135,8765 & 136,9863 & 0,0086 & 0,9999 \\
\hline CCA & 130,9653 & 133,3333 & 0,0034 & 0,9995 \\
\hline CBC & 125,5084 & 126,5823 & 0,0027 & 0,9994 \\
\hline
\end{tabular}

O modelo de difusão intraparticular Equação 3, não foi bem sucedido em representar os dados de sorção dos materiais estudados, conforme se pode observar na Figura 4.

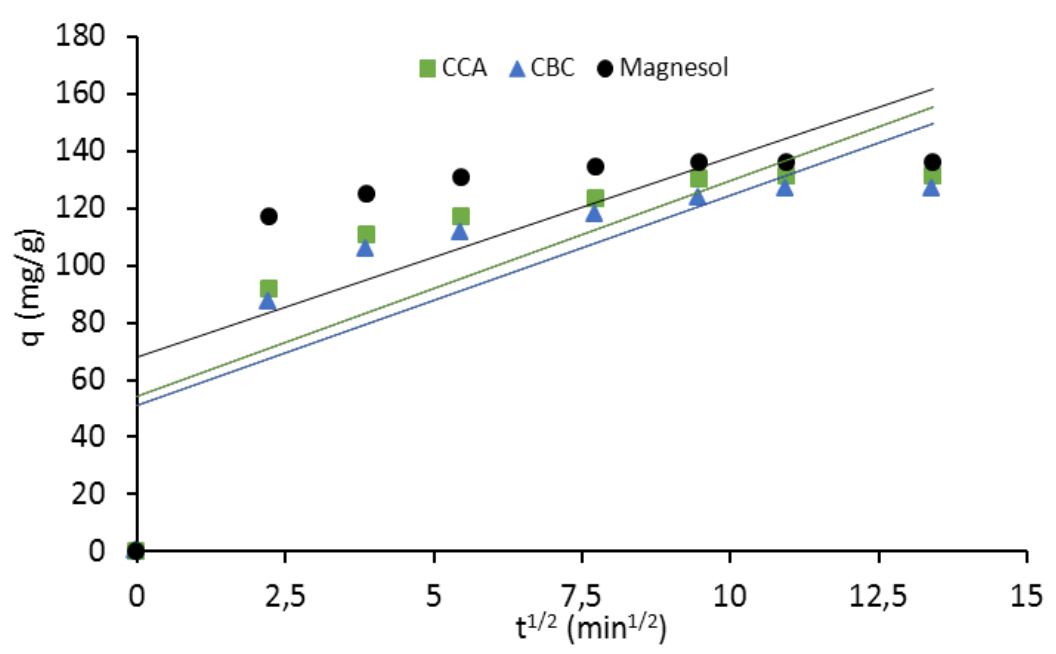

Figura 4 - Ajustes com o modelo cinético de difusão intraparticular. 
$\mathrm{Na}$ Tabela 4 estão os coeficientes de regressão obtidos pela aplicação do modelo de difusão intraparticular aos dados experimentais, demonstrando que a aplicação do mesmo não foi satisfatória.

Tabela 4 - Coeficientes de regressão obtidos pelo modelo de difusão intraparticular.

\begin{tabular}{|c|c|c|c|}
\hline Adsorventes & Magnesol $^{\circledR}$ & CBC & CCA \\
\hline Coef. de Regressão $\left(\mathrm{R}^{2}\right)$ & 0,4689 & 0,6189 & 0,6105 \\
\hline
\end{tabular}

O melhor ajuste pelo modelo de pseudo-segunda ordem, para os três materiais avaliados, pode ser explicado pelo fato de que tanto o adsorbato em estudo (glicerol livre) quanto o meio no qual este se encontra disperso (biodiesel) são orgânicos. Trata-se, portanto, de um meio com mobilidade iônica baixa, levando ao pressuposto de que a adsorção do glicerol livre nos materiais estudados é física. A adsorção física depende da disponibilidade de área superficial livre nas partículas do adsorvente. Desta forma, no início do processo a adsorção ocorre rapidamente, visto que há muita área livre nesse momento, e quanto mais próximo do equilíbrio, mais lenta será a adsorção. Tal comportamento não-linear pode ser descrito por uma equação quadrática, sendo possivelmente esse o motivo pelo qual o modelo de pseudo-segunda ordem representou melhor o processo.

\section{CONCLUSÃO}

Baseando-se nos resultados obtidos, pode-se concluir que os adsorventes alternativos cinca da casca de arroz (CCA) e cinza do bagaço de cana-de açúcar (CBC) - foram eficientes na purificação do biodiesel, reduzindo o teor de glicerol livre (GL) ao nível especificado pela ANP $(0,02 \%$ em massa) e apresentando capacidades adsortivas próximas às do padrão comercial - Magnesol ${ }^{\circledR}$.

Dentre os três modelos de cinética avaliados, o modelo de pseudo-segunda ordem foi o que se adequou aos resultados, para todos os materiais avaliados. As capacidades adsortivas e os tempos necessários para atingir o equilíbrio foram, respectivamente: $135,87 \mathrm{mg} / \mathrm{g}$ e 60 minutos para o Magnesol $^{\circledR} ; 130,96 \mathrm{mg} / \mathrm{g}$ e 90 minutos para a CCA e $125,5 \mathrm{mg} / \mathrm{g}$ e 120 minutos para a CBC.

Os materiais mostraram bom desempenho para sorção em batelada, mas o fato de a CCA, a CBC e o Magnesol ${ }^{\circledR}$ apresentarem-se sob a forma de pós pode prejudicar a aplicação dos mesmos em processos contínuos, ocasionando problemas de fluxo. Para contornar esse problema, sugere-se o estudo da peletização desses materiais em trabalhos futuros.

De modo geral, a sorção em materiais alternativos de baixo custo (CCA e CBC) mostrou-se um método adequado para a remoção de traços de GL do biodiesel, podendo ser um método indicado para substituir a usual etapa de lavagem aquosa dos ésteres, a qual é prejudicial por gerar grande volume de efluentes e pela propensão à formação de emulsões.

\section{NOMENCLATURA}

C: Constante que representa o coeficiente linear do modelo de difusão intraparticular (mg sólido/g sorvente) 
$\mathrm{k}_{1}$ : Constante da equação cinética de pseudo-primeira ordem $\left(\mathrm{min}^{-1}\right)$

$\mathrm{k}_{2}$ : Constante da equação cinética de pseudo-segunda ordem (g sorvente/mg sólido. min)

ki: Constante de difusão intraparticular ( $\mathrm{mg}$ sólido/g sorvente. $\mathrm{min}^{1 / 2}$ )

$\mathrm{q}_{\mathrm{e}}$ : Quantidade de sólido presente no sorvente no equilíbrio (mg sólido/g sorvente)

$\mathrm{q}_{\mathrm{t}}$ : Quantidade de sólido presente no sorvente no tempo $\mathrm{t}$ (mg sólido/g sorvente)

t: Tempo (min)

\section{REFERÊNCIAS}

ANP - Agência Nacional do Petróleo, Resolução ANP Nº14, de 11 de maio de 2012.

ATKINS, P.W. Físico Química. Volume 3, 7ª ed. Wiley: New York, 2002.

COSTA NETO, P.R.; ROSSI, L.F.S.; ZAGONEL, G.F.; RAMOS, L.P. Produção de biocombustível alternativo ao óleo diesel através da transesterificação de óleo de soja usado em frituras. Química Nova, vol.23, n.4, 2000.

DE PAULA, A.J.A.; KRUGEL, M.; MIRANDA, J.P.; ROSSI, L.F.S.; NETO, P.R.C. Utilização de argilas para purificação de biodiesel. São Paulo: Química Nova, 2011.

GUI, M.M.; LEE, K.T.; BHATIA, S. Feasibility of edible oil vs. nonedibleoil vs. waste edible oil as biodiesel feedstock. Energy, v. 33, n. 11, p. 1646-1653, 2008.

OM TAPANES, N.C. et al. Biodiesel no Brasil: Matérias primas e tecnologias de produção. Acta Scientiae e Technicae. V. 1, n 1. Fevereiro, 2013.

ROYER, B. Remoção de corantes têxteis utilizando casca de semente de Araucária angustifólia como biossorvente. Dissertação de Mestrado, UFRGS, 2008.

SILVA, P. R. F.; FREITAS, T. F. S. Biodiesel: o Ônus e o Bônus de Produzir Combustível. Ciência Rural, Santa Maria, v.38, n. 3, p. 843-851, mai/jun. 2008. 